\title{
The effect of intravenous magnesium sulfate infusion on reduction of pain after abdominal hysterectomy under general anesthesia: a double-blind, randomized clinical trial
}

\author{
Mohammad Hossein Jarahzadeh ${ }^{1}$, Sina Taghizadeh Harati ${ }^{2}$, Hamideh Babaeizadeh², Elahe Yasaei $^{2}$, Farshid \\ Rahimi Bashar ${ }^{3}$
}

${ }^{1}$ Department of Anesthesiology and Critical Care, Pain Research Center, Shahid Sadoughi University of Medical Sciences, Yazd, Iran

${ }^{2}$ Department of Anesthesiology, Shahid Sadoughi University of Medical Sciences, Yazd, Iran

${ }^{3}$ Department of Anesthesiology and Critical Care, School of Medicine, Hamadan University of Medical Sciences, Hamadan, Iran

\section{Type of article: Original}

\begin{abstract}
Background: Post-surgical pain is a physiological response to tissue trauma that produces unpleasant physiological effects with manifestations on various organic systems.

Objective: According to the effect of magnesium sulfate on the N-methyl-d-aspartate (NMDA) receptor, this study examined the effect of magnesium sulfate on the reduction of pain and the mean amount of narcotics consumed by patients after abdominal hysterectomies.

Methods: This double-blind clinical trial study was performed on 60 patients who had undergone abdominal hysterectomies in Shahid Sadoughi Hospital in Yazd, Iran, from 2013 to 2015. The patients were divided randomly into two groups of 30 members each. All of the patients received $2 \mathrm{mg}$ of Midazolam and $2 \mathrm{mcg} / \mathrm{kg}$ of Fentanyl as the induction of anesthesia with propofol $(2-2.5 \mathrm{mg} / \mathrm{kg})$ and Atracurium $0.5 \mathrm{mg} / \mathrm{kg}$ was conducted. All of the patients received $5 \mathrm{mg}$ of intravenous morphine $30 \mathrm{~min}$ after induction of anesthesia. Afterwards, the study group received $50 \mathrm{mg} / \mathrm{kg}$ of magnesium sulfate in $500 \mathrm{~cm}^{3}$ of Ringer's serum during the 20 minutes, and $500 \mathrm{~cm}^{3}$ of Ringer's serum was administered to the members of the placebo group. Visual analogue scale VAS scores were evaluated to reach the minimum difference of 0.8 in mean pain score

Results: The results of this study indicated that the mean pain scores immediately after surgery and at $1,2,6$, and $12 \mathrm{hr}$ after surgery were lower in the study group than in the placebo group. The mean value of narcotic consumption at all measured time points was higher in the placebo group. No significant differences were found between two groups concerning drug complications.

Conclusion: The results of this study indicated that the intravenous injection of magnesium sulfate can reduce pain, reduce morphine consumption, and reduce the side effects of morphine in patients after surgery.

Funding: This study was funded by Shahid Sadoughi University of Medical Sciences, Yazd, Iran

Clinical trial registration: The trial was registered at the Thai Clinical Trials Registry (http://www.clinicaltrials.in.th) with the registration ID: TCTR20160308001.

Funding: This study was funded by Shahid Sadoughi University of Medical sciences, Yazd, Iran.

Keywords: Magnesium sulfate; Pain; Hysterectomy; Anesthesia; Analgesic
\end{abstract}

\section{Introduction}

Post-surgical pain is a complex physiological response to tissue trauma that produces extremely unpleasant physiological effects with manifestations on various organic systems resulting in remarkable morbidity. With the development of the epidemiological and physiological awareness of pain, more attention has been focused on

\section{Corresponding author:}

Farshid Rahimi Bashar, Department of Anesthesiology and Critical Care, School of Medicine, Hamadan University of Medical Sciences, Hamadan, Iran.

Tel: +98.9125816621, Fax:+98.3538224100, Email: farshidbashar2015@gmail.com

Received: December 28, 2015, Accepted: April 03, 2016, Published: July 2016

iThenticate screening: April 03, 2016, English editing: April 17, 2016, Quality control: June 24, 2016

(C) 2016 The Authors. This is an open access article under the terms of the Creative Commons Attribution-NonCommercialNoDerivs License, which permits use and distribution in any medium, provided the original work is properly cited, the use is non-commercial and no modifications or adaptations are made. 
patients under treatment and pain control following surgery. Efforts have also been directed at making the process as convenient as possible for patients, decreasing the mortality rate, and reducing costs by reducing the length of stay in the post-anesthesia care units (1). Uncontrolled pain after surgery can activate the sympathetic nervous system and lead to morbidity and mortality. Sympathetic nervous system increases myocardial oxygen consumption, which causes the extension of ischemia and even myocardial infarction $(2,3)$. In most cases, induction of general anesthesia is done by intravenous drugs, which cause rapid loss of consciousness. Important things during general anesthesia include blocking memory of the procedure (amnesia), pain relief (analgesia), relaxing the skeletal muscles, and control of the sympathetic nervous system, induced by intense stimulation (1). Various approaches for treating pain after surgery are available, including systematic and topical analgesics, such as opioids, ketamine, and tramadol (4). Opioid analgesics are a proper way to control patients' pain after surgery. These drugs have effects on the $(\mu)$ receptors in the central nervous system, and they also affect the peripheral opioid receptors (4). Acute opioid prescription has analgesic effects but also can produce complications, such as nausea, vomiting, sedation, and respiratory depression. It seems that both tolerance and dependence can occur after chronic prescription of opioids, although it has been observed that both can occur quickly after acute administration, both in animals and in people (5). According to the antagonistic effect on N-methyl-d-aspartate (NMDA) receptor, magnesium sulfate can have an analgesic effect. Many clinical research have indicated that the injection of magnesium during general anesthesia decreases the demand for anesthetics and analgesics after surgery (6-9). With decrease in the activity of the neuromuscular synaptic sites, magnesium sulfate decreases the irritability of the central nervous system, and it also can cause the uterus to relax. Clinically, the therapeutic effect of magnesium sulfate is characterized by a decrease in the tendon deep reflex response, and significant attenuation of this reflex is a symptom of magnesium toxicity (1). Of the available magnesium sulfate, $25-35 \%$ is bound to plasma proteins. Minerals that contain magnesium enter the body via an injection, and they are excreted in the urine. The action of the drug begins an hour after intramuscular injection and immediately after intravenous injection. This drug should not be used in patients with heart block and acute kidney failure (renal insufficiency) (10). Magnesium sulfate overdose leads to elevated levels of magnesium in the blood and its important signs are suppression of nervous reflexes, respiratory weakness caused by neuromuscular disorder, nausea, vomiting, skin redness (erythema), thirst, low blood pressure due to peripheral vascular ectasia (dilation), dizziness, confusion, difficulty with speech, muscle weakness (myasthenia), diplopia, bradycardia, coma, and cardiac arrest (10). Hysterectomy is one of the prevalent types of surgery, which has always been the only approved treatment for dysfunctional uterine bleeding (DUB), and the patient's satisfaction with the results was higher than with the results of alternative treatments. In most cases, hysterectomy is done through the abdomen; however, surgery through a small incision in the vagina usually has fewer complications (11). Abdominal hysterectomy is mainly done through a surgical incision called a pfannenstiel incision; however, for 24-48 hours after surgery, patients are likely to feel noticeable pain and will most likely require prescriptions for narcotic pain medications (12). Based on the fact that magnesium sulfate decreases irritations of the central nervous system, we decided to investigate its effect on reducing pain in patients after abdominal hysterectomy surgery. With the extension of awareness in epidemiology and physiopathology of pain, more attention is paid to treatment and pain control in patients after surgery, and attempts have been made to provide patients relief from pain while decreasing both the mortality rate and the costs of health care while simultaneously reducing the length of their stays in intensive care units (ICUs) and hospital rooms.

\section{Material and Methods}

\subsection{Trial Design, participants, and ethics}

This study was a double-blind, randomized, clinical trial (RCT), and it was approved by the Ethics Committee of Yazd University of Medical Sciences. After obtaining written informed consent from patients, abdominal hysterectomy surgery was done on 60 candidate patients in the age range of 35-65 with the physical status of ASA1, 2 (American Society of Anesthesiologists) in Shahid Sadoughi Hospital in Yazd, Iran, from 2013 to 2015.

\subsection{Exclusion criteria}

Exclusion criteria in the current study were women under age 35 and over 65, patients addicted to narcotics, patients who already had pulmonary, heart and kidney disease, and patients who were known to be allergic to magnesium sulfate.

\subsection{Intervention}

In this study, the patients were divided into two groups that according to similar studies and $p$-value $=0.05$, Standard deviation of visual analogue scale (VAS) $(\mathrm{SD}=1)$, reaching the minimum difference of 0.8 in mean pain score, each group required 26 patients; there were 30 patients in each of our groups. All of the patients received $2 \mathrm{mg}$ of 
Midazolam and $100 \mathrm{mcg}$ of Fentanyl as the induction of anesthesia with propofol (2-2.5 $\mathrm{mg} / \mathrm{kg})$ and Atracurium 0.5 $\mathrm{mg} / \mathrm{kg}$ was conducted. All patients received $5 \mathrm{mg}$ of morphine intravenously $30 \mathrm{~min}$ after induction of anesthesia. Afterwards, $50 \mathrm{mg} / \mathrm{kg}$ of magnesium sulfate in $500 \mathrm{~cm}^{3}$ of Ringer's serum were administered over a 20-min period in the study group, and $500 \mathrm{~cm}^{3}$ of Ringer's serum was administered in placebo group; they were unaware what was being administered. All of the surgeries were performed by the same team of surgeons. VAS scores were evaluated and recorded by an anesthesiologist assistant.

\section{Results}

This study was performed on 60 patients who had undergone hysterectomy surgery. The patients were divided into two groups of 30 patients each based on a random number table. The mean age of the patients in the placebo group was $52 \pm 6.95$, and it was $51 \pm 7.6$ in the study group; there was no significant difference between them $(\mathrm{p}<0.05)$. The mean weight of the patients in the placebo group was $66 \pm 5.64 \mathrm{Kg}$, and it was $68 \pm 9.86 \mathrm{Kg}$ in the study group, i.e., there was no significant difference between them $(\mathrm{p}<0.05)$. The pain the patients experienced was measured based on the VAS score at time points of 1-12 hours after surgery on the basis of the t-test, as shown in Table 1. The data indicate that the mean pain was significantly different between the two groups at all measured time points. The mean pain scores at all time-points (immediately after surgery and 1, 2, 6, and 12 hours after surgery) were measured. The mean values of pain were lower in the study group than in the placebo group (Table 1$)(\mathrm{p}=0.009$, 0.026, 0.0001, 0.043, 0.003; immediately after surgery and 1, 2, 6, and 12 hours after surgery respectively). The means of narcotic consumption for all measured time points (immediately after surgery and 1, 2, 6, and 12 hours after surgery) between the placebo and study groups were significantly different, with the values being higher in the placebo group (Table 2$)(\mathrm{p}=0.004,0.0001,0.0001,0.0001 ; 1$ hours after surgery and $1,2,6$, and 12 hours after surgery, respectively). After investigating the complications of drugs, no significant difference was found between the two study groups. By comparison, the frequency distribution of drowsiness at time points of "immediately after surgery" and "one hour after surgery" in two study groups, according to the Chi-square test, the difference was not significant. It was concluded that there was a significant difference between the two groups; the mean pain score was lower in the study group at all measured time points, whereas no significant difference was found between the placebo and study groups at the time point of $6 \mathrm{hr}$ after surgery. According to the table above, the one-way repeated measure test, and the significance level of 0.05 , a statically significant difference was found in mean morphine consumption during measured time points between the two study groups, with the consumption being higher at all measured time points in the placebo group.

Table 1. Comparison of the mean pain scores in the two study groups at various time points

\begin{tabular}{|l|l|l|l|l|l|}
\hline Group & \multicolumn{2}{|l|}{ Pain score (Mean \pm SD) } & \multicolumn{2}{l|}{$\begin{array}{l}12 \text { hours after } \\
\text { surgery }\end{array}$} \\
\cline { 2 - 6 } & $\begin{array}{l}\text { Immediately } \\
\text { After surgery }\end{array}$ & 1 hour after surgery & $\begin{array}{l}\text { 2 hours after } \\
\text { surgery }\end{array}$ & hours after surgery & $3.43 \pm 0.97$ \\
\hline Study group & $8.76 \pm 1.04$ & $8.10 \pm 0.99$ & $7.00 \pm 1.33$ & $5.53 \pm 1.43$ & $4.16 \pm 0.83$ \\
\hline Placebo group & $9.36 \pm 0.61$ & $8.60 \pm 0.67$ & $8.03 \pm 0.55$ & $7.03 \pm 0.76$ & 0.003 \\
\hline p-value & 0.009 & 0.026 & 0.0001 & 0.043 & \\
\hline
\end{tabular}

Table 2. Comparison of mean morphine consumption at various time points in the two study groups

\begin{tabular}{|l|l|l|l|l|l|}
\hline Group & \multicolumn{4}{l|}{ Morphine intake (Mean \pm SD) } \\
\cline { 2 - 6 } & $\begin{array}{l}\text { Immediately } \\
\text { after surgery }\end{array}$ & 1 hour after surgery & $\begin{array}{l}2 \text { hours after } \\
\text { surgery }\end{array}$ & $\begin{array}{l}\text { 6 hours after } \\
\text { surgery }\end{array}$ & $\begin{array}{l}12 \text { hours after } \\
\text { surgery }\end{array}$ \\
\hline Study group & - & $0.82 \pm 0.05$ & $1.60 \pm 0.09$ & $3.49 \pm 0.14$ & $8.13 \pm 0.23$ \\
\hline Placebo group & - & $0.86 \pm 0.04$ & $1.69 \pm 0.06$ & $3.71 \pm 0.13$ & $8.59 \pm 0.18$ \\
\hline p-value & - & 0.004 & 0.0001 & 0.0001 & 0.0001 \\
\hline
\end{tabular}

\section{Discussion}

Hysterectomy is one the most prevalent surgeries for treatment of dysfunctional uterine bleeding (DUB) and it has the highest patients satisfaction in comparison with other alternative treatments. In most cases hysterectomies are done through the abdomen, although surgery through a small incision in the vagina usually has fewer complications (11). Abdominal hysterectomy is mainly done through a surgical incision called the pfannenstiel incision, albeit in 24 to 48 hours after surgery patients experience more pain and need more morphine (12). In the case of lack of pain relief and stimulation of sympathetic nervous system, important complications are produced in patients, such as pain after surgery, which causes hypertension, and cardiac ischemia can occur in susceptible patients. For postoperative 
analgesia, many methods have been investigated that produced different results (4). The use of intravenous narcotics may lead to respiratory depression in patients. Therefore, to prevent this associated complication, many different drugs have been tried in efforts to minimize complications (5). Related to its antagonistic effect on NMDA receptor, magnesium sulfate can have an analgesic effect, so that many clinical research have shown that the injection of magnesium during general anesthesia decreases demands for anesthetics and analgesics after surgery (6-9). The use of magnesium sulfate in different methods has been studied for pain relief after surgery. In a study by Ryh et al. (2006) on 60 patients who were candidates for hysterectomy, after the preoperative prescription of $50 \mathrm{mg} / \mathrm{kg}$ of magnesium sulfate and $15 \mathrm{mg} / \mathrm{kg} / \mathrm{h}$ during abdominal hysterectomy surgery, it was seen that the pain score and total rate of morphine use in the magnesium group was remarkably lower than in the placebo group (8). In our study, the effect of the intravenous injection of $50 \mathrm{mg} / \mathrm{kg}$ of magnesium sulfate with placebo was compared to the postoperative consumption of narcotics in pain relief after surgery. The results of a recent study showed that prescribing $50 \mathrm{mg} / \mathrm{kg}$ of magnesium sulfate during surgery reduced the pain after surgery and reduced the amount of morphine intake in the first 12 hours to a greater extent than in the control group. According to the stronger effect of magnesium sulfate on relaxation, it was found no difference in two groups. In a study by Kahraman et al. (2014) on 40 patients who had undergone abdominal hysterectomy surgery under spinal anesthesia, it was shown that pain score and the amount of morphine intake in a group that had received $60 \mathrm{mg} / \mathrm{kg}$ magnesium during surgery was lower compared to the patients in the placebo group, who had received normal saline. By comparison, the type of anesthesia and the dose rate of magnesium sulfate in our study was different (13). A study was done by Sayhan et al. on 26 women who were divided into four groups. Group 1 received $40 \mathrm{mg} / \mathrm{kg}$ of magnesium sulfate before surgery and $20 \mathrm{mg} / \mathrm{kg}$ of magnesium sulfate four hours after surgery. Group 2 received $40 \mathrm{mg} / \mathrm{kg}$ of magnesium sulfate before anesthesia and $10 \mathrm{mg} / \mathrm{kg}$ of magnesium sulfate four hours after surgery. Group $3 \mathrm{received} 40 \mathrm{mg} / \mathrm{kg} \mathrm{of}$ magnesium sulfate before surgery and normal saline four hours after surgery. Group 4 also only received normal saline before anesthesia. The results revealed that the magnesium group needed a lower rate of propofol than the control group. And the amount of morphine total consumption was remarkably higher in the control group than that in the magnesium sulfate group (14). The different point in the aforementioned study compared to the present study was $40 \mathrm{mg} / \mathrm{kg}$ of magnesium before anesthesia and 10-20 mg/kg magnesium four hours after surgery; the amount of morphine consumption was lower in the group of patients who received magnesium sulfate in both studies. A study was done by Hwang et al. on 40 patients who had undergone total hip replacement surgery under spinal anesthesia; pain score and the amount of morphine intake at time points of 4, 24, and 48 hours after surgery in the group who had received $50 \mathrm{mg} / \mathrm{kg}$ of magnesium bolus injection in 15 minutes and $15 \mathrm{mg} / \mathrm{kg} / \mathrm{h}$ afterwards was lower than the patients in the group, who had received normal saline. This result was obtained in a case that type of surgery, anesthesia type, and continuous dose of $15 \mathrm{mg} / \mathrm{kg} / \mathrm{h}$ during surgery were different from our study (15). In a study done by Dabbagh et al., 60 patients underwent lower extremity orthopedic surgery under spinal anesthesia; the pain score 12 hours after surgery and the amount of morphine consumption in the first 24 hours after surgery in a group of patients who received $8 \mathrm{mg} / \mathrm{kg}$ of magnesium sulfate before surgery was lower than the placebo group (normal saline) (16). The results of the aforementioned study were almost similar to our findings. In a study by $\mathrm{Na}$ on 61 patients with cerebral palsy (CP) who had undergone orthopedic surgery, pain score, the dose of rocuronium, and the use of analgesic drugs in the group who had received $50 \mathrm{mg} / \mathrm{kg}$ of magnesium sulfate bolus injection and then 15 $\mathrm{mg} / \mathrm{kg}$ during surgery was lower than the placebo group (17). In another study that was done in 2008 on 48 patients by Benhaj Amor, pain score and the amount of morphine consumption in the group who had received $50 \mathrm{mg} / \mathrm{kg}$ of magnesium sulfate before surgery and $0.5 \mathrm{~g} / \mathrm{h}$ after surgery was lower compared to the group who had received normal saline. The results of aforementioned study were similar to our study, according to the difference in rate of magnesium sulfate prescription (16). The side effects of magnesium sulfate included repression of nervous reflexes, respiratory weakness due to neuromuscular disorders, nausea, vomiting, skin redness (erythema), thirst, low blood pressure due to peripheral vascular ectasia, dizziness, confusion, difficulty with speech, muscle weakness (myasthenia), diplopia, bradycardia (bradyarrhythmia), coma, and cardiac arrest; we evaluated the repression of nervous reflexes, respiratory weakness, and drowsiness according to similar research, and it no significant difference was found in the results that were obtained. No complications have been observed in patients in similar studies (10).

\section{Conclusions}

According to the results of this study, the pain scores and mean of narcotic consumption in measured time points were lower in the patients who received magnesium sulfate than in the placebo group. Regarding the post-operative pain of patients after abdominal hysterectomy and the necessity of care time after injection of morphine, we suggest an intravenous injection of magnesium sulfate because of its ability to decrease post-operative pain and subsequently to reduce morphine consumption and the associated side effects, as well as to decrease the time require d for postoperative care. 


\section{Acknowledgments:}

This study is a result of medical student thesis and was supported by Shahid Sadoughi University of Medical Sciences, Yazd, Iran.

\section{Conflict of Interest:}

There is no conflict of interest to be declared.

\section{Clinical trial registration:}

The trial was registered at the Thai Clinical Trials Registry (http://www.clinicaltrials.in.th) with the registration ID: TCTR20160308001.

Funding: This study was funded by Shahid Sadoughi University of Medical Sciences, Yazd, Iran

\section{Authors' contributions:}

All authors contributed to this project and article equally. All authors read and approved the final manuscript.

\section{References:}

1) Miller RD, Pardo M. Basics of Anesthesia Sixth edition 2011.

2) $\mathrm{Wu} \mathrm{CL}$, Fleisher LA. Outcomes research in regional anesthesia and analgesia. Anesth Analg. 2000; 91(5): 1232-42. PMID: 11049915.

3) Liu S, Carpenter RL, Neal JM. Epidural anesthesia and analgesia, Their role in postoperative outcome. Anesthesiology. 1995; 82(6): 1474-506. PMID: 7793661.

4) Stein C. The control of pain in peripheral tissue by opioids. N Engl J Med. 1995; 332(25): 1685-90. PMID: 7760870 .

5) Kissin I, Brown PT, Robinson CA, Bradley EL Jr. Acute tolerance in morphine analgesia: continuous infusion and single injection in rats. Anesthesiology. 1991; 74(1): 166-71. PMID: 1986642.

6) Tramer MR, Schneider J, Marti RA, Rifat K. Role of magnesium sulfate in postoperative analgesia. Anesthesiology. 1996; 84(2): 340-7. PMID: 8602664.

7) Ryu JH, Kang MH, Park KS, Do SH. Effects of magnesium sulphate on intraoperative anaesthetic requirements and postoperative analgesia in gynaecology patients receiving total intravenous anaesthesia. Br J Anaesth. 2008; 100(3): 397-403. doi: 10.1093/bja/aem407. PMID: 18276652.

8) Ozcan PE, Tugrul S, Senturk NM, Uludag E, Cakar N, Telci L, et al. Role of magnesium sulfate in postoperative pain management for patients undergoing thoracotomy. J Cardiothorac Vasc Anesth. 2007; 21(6): 827. PMID: 18068060.

9) Koinig H, Wallner T, Marhofer P, Andel H, Horauf K, Mayer N. Magnesium sulfate reduces intra- and postoperative analgesic requirements. Anesth Analg. 1998; 87(1): 206-10. PMID: 9661575.

10) R K. Daroohay generic Iran 5, editor. Iran: Dibaj. 2009; 529-74.

11) Manyonda. Total abdominal hysterectomy, In: O'Donovan PJ MC, editor, Modern Management of Abnormal Uterine Bleeding. London: Informa Healthcare. 2008; 267-79. doi: 10.3109/9780203091524-40.

12) Ng A, Smith G, Davidson AC. Analgesic effects of parecoxib following total abdominal hysterectomy. Br J Anaesth. 2003; 90(6): 746-9. doi: 10.1093/bja/aeg139. PMID: 12765890.

13) Kahraman F, Eroglu A. The effect of intravenous magnesium sulfate infusion on sensory spinal block and postoperative pain score in abdominal hysterectomy. Biomed Res Int. 2014; 2014: 236024. doi: $10.1155 / 2014 / 236024$.

14) Seyhan TO, Tugrul M, Sungur MO, Kayacan S, Telci L, Pembeci K, et al. Effects of three different dose regimens of magnesium on propofol requirements, haemodynamic variables and postoperative pain relief in gynaecological surgery. Br J Anaesth. 2006; 96(2): 247-52. doi: 10.1093/bja/aei291. PMID: 16311277.

15) Hwang JY, Na HS, Jeon YT, Ro YJ, Kim CS, Do SH. I.V. infusion of magnesium sulphate during spinal anaesthesia improves postoperative analgesia. Br J Anaesth. 2010; 104(1): 89-93. doi: 10.1093/bja/aep334. PMID: 19933175.

16) Dabbagh A, Elyasi H, Razavi SS, Fathi M, Rajaei S. Intravenous magnesium sulfate for post-operative pain in patients undergoing lower limb orthopedic surgery. Acta Anaesthesiol Scand. 2009; 53(8): 1088-91. doi: 10.1111/j.1399-6576.2009.02025. PMID: 19519724.

17) Na HS, Lee JH, Hwang JY, Ryu JH, Han SH, Jeon YT, et al. Effects of magnesium sulphate on intraoperative neuromuscular blocking agent requirements and postoperative analgesia in children with cerebral palsy. Br J Anaesth. 2010; 104(3): 344-50. doi: 10.1093/bja/aep379. PMID: 20042475. 